and multivariate comparative analyisis was performed, in order to define which variables were related to the negativity or positivity of HLAB27.

Results: Data of 1235 AS pacients were analysed. Of them 1029 (83.3\%) were HLAB27 positive and 206 (17.7\%) HLAB27 negative. 924 (74.8\%) were men. AS patients with HLAB27+ presented significantly more familiar history of spondyloarhritis $(p=0.002)$, were younger $(p=0.012)$ and had earlier disease onset and disease diagnosis $(p<0.001)$, with a longer disease duration $(p=0.037)$ and a trend to a higher percentage of uveitis compared to those with HLAB27-. On the other hand, AS patients with HLAB27- also presented significantly more peripheral arthritis $(p=0.0022)$, dactylitis $(p=0.001)$ and extraarticular manifestations (psoriasis, palmoplantar pustulosis, inflammatory bowel disease (IBD) and balanitis $(p<0.001))$ compared with those of HLAB27+. AS patients with HLAB27- also presented higher scores of BASDAI and BASFI ( $p=0.047$ and $p=0.005$ respectively). The study didn't show differences between both groups of patients regarding sex distribution, axial manifestations, enthesitis nor radiological damage (assessed by $\mathrm{BASRI}$ ). In the multivariate analysis, the family history of spondyloarthritis (OR 2.10, IC95\% 1.27-3.49, p=0.004), the age at diagnosis (OR 0.97, IC95\% $0.96-0.98, \mathrm{p}<0.001$ ), the presence of dactylitis (OR 0.16, IC95\% $0.05-0.56$, $\mathrm{p}=0.004$ ), extraarticular manifestation specially IBD (OR 0.22, IC95\% $0.12-0.40$, $\mathrm{p}<0.001$ ) and peripheral arthritis (OR 0.53 , IC95\% $0.32-0.89, \mathrm{p}=0.016$ ) were the variables independently associated with the presence of HLAB27.

Conclusions: The presence of HLAB27 in AS patients is associated to an earlier disease onset, a higher frequency of familiar history of spondyloarthritis, and a lower frequency of dactylitis, extraarticular manifestations and peripheral arthritis. Disclosure of Interest: None declared

DOI: 10.1136/annrheumdis-2017-eular.1928

\section{SAT0411 CORRELATION BETWEEN DISEASE ACTIVITY SCORES AND QUALITY OF LIFE IN SPONDYLOARTHRITIS}

M. Linda, K. Baccouche, S. Lataoui, S. Belghali, Z. Alaya, N. El Amri, H. Zeglaoui, E. Bouajina. Rheumatology, Farhat Hached Hospital, Sousse, Tunisia

Background: Spondyloarthritis ( $\mathrm{SpA}$ ) is a group of chronic inflammatory rheumatism and it is known to be one of the leading causes of disability.

Objectives: This study aimed to investigate the quality of life and the psychological disorders (depression, anxiety and insomnia) in patients with SpA

Methods: A total of 60 patients were included with the diagnosis of SpA meeting the Amor and New York modified criteria, in a prospective study. In a questionnaire, the characteristics of the disease and sociodemographic patient were collected. Also psychiatric assessment was done using the insomnia severity index score (ISI) and the Hospital Anxiety and Depression scale (HAD). In addition, patients answered to the Ankylosing Spondylitis Quality of Life (ASQoL) questionnaire and the SF-12.

Results: The sex-ratio (men/women) was 3.28 (46/14), the average age was 37.95 years (18-70). The average duration of disease progression was 11.5 years (1-30). The mean value of the Bath Ankylosing Spondylitis Disease Activity Index (BASDAl) was 5.11 and the Bath Ankylosing Spondylitis Functional Index (BASFI) was 5.22 . Uveitis was reported in $11.7 \%$ of patients, osteoporosis in $35 \%$, enthesitis in $36.7 \%$ and coxitis in $36.7 \%$. $78.3 \%$ of patients received NSIAD and $30 \%$ were treated with biotheraby. On the psychological level, $25 \%$ of patients had an anxiety, $20 \%$ had depression. According to the ISI, $35 \%$ of patients had sub threshold insomnia, $20 \%$ had moderate insomnia and $10 \%$ had severe insomnia. The mean value of the ASQoL was $9(0-16)$. The mean value of the physical health was $37.13(19.34-60.41)$ and for the mental health was 41.65 (14.9-60.35). A significant positive correlation was found between the disease activity and the ASQoL $(p=0.000)$, the physical health $(p=0.000)$ and the mental health $(p=0.002)$. Also, we found a significant positive correlation between the BASDAl and depression $(p=0.01)$ and insomnia $(p=0.001)$.

Conclusions: SpA is a chronic inflammatory disease that contributes to significant physical disability and decreased quality of life in a significant number of patients. The treatment of those patients must consider the improvement of quality of life, as part of a global approach.

Disclosure of Interest: None declared

DOI: 10.1136/annrheumdis-2017-eular.6394

\section{SAT0412 ASSOCIATION BETWEEN SMOKING WITH SPINAL LEVEL OF STIFFNESS AND FUNCTIONAL LIMITATION IN PATIENTS WITH AXIAL SPONDYLOARTHRITIS: RESULTS FROM THE SPANISH ATLAS}

M. Garrido-Cumbrera ${ }^{1}$, J. Chacón-García ${ }^{1}$, J. Gratacos-Masmitja ${ }^{2}$,

D. Galvez-Ruiz ${ }^{1}$, V. Navarro-Compan ${ }^{3}$, C. Blanch-Mur ${ }^{4}$, E. Collantes-Estevez ${ }^{5}$

P. Zarco-Montejo ${ }^{6}$, O. Brace ${ }^{1} .{ }^{1}$ Universidad de Sevilla, Seville; ${ }^{2} \mathrm{H}$. Parc Taulí,

Sabadell; ${ }^{3}$ H. la Paz, Madrid; ${ }^{4}$ Novartis, Barcelona; ${ }^{5}$ Universidad de Córdoba,

Cordova; ${ }^{6}$ H. Fundación Alarcón, Madrid, Spain

Background: Smoking has been associated with greater disease activity and radiographic progression in patients with Axial Spondyloarthritis (ax-SpA). In addition, radiographic damage has been linked to greater functional limitation. However, clarification is still being sought as to whether or not this association exists. Objectives: To investigate the association between smoking and both the area of spinal stiffness and functional limitation in patients with ax-SpA.
Methods: A sample of 680 patients diagnosed with ax-SpA was interviewed during 2016 as part of the Spanish Atlas, which aims to promote early referral and improve healthcare and the use of effective treatments in patients with ax-SpA. Tobacco consumption was recorded as: Smoker (62.4\%), Occasional Smoker $(8.9 \%)$ and Non-Smoker $(28.7 \%)$. Spinal stiffness was assessed in the three different vertebral areas: cervical, dorsal and lumbar.

To determine de degree of functional limitation we used a composed index which includes the sum of the degree of limitation in the 18 daily activities well established (dressing, grooming, bathing, tying shoelaces, moving around the home, stairs, getting to/out of bed, toilet, shopping, preparing meals, eating, cleaning, walking, using public transportation, going to the doctor, driving, physical exercise, sexual relations) using an ordinal variable $(0=$ none, $1=$ little, $2=$ some and $3=$ moderate). A descriptive analysis was used to compare the level of stiffness (chi-squared test) and the mean degree of limitation (Kruskal-Wallis test) in the different groups of smokers consumptions. Regression analysis was also used to assess the relation between smoking and degree of limitation (0-54).

Results: $53 \%$ were females, mean age 46 years and $77.1 \%$ were HLA-B27+ The percentage of patients with stiffness in the lumbar region was significantly higher in habitual/occasional smokers than in non-smokers $(89.0 \%, 93.8 \%$, $83.5 \%$ respectively; $p<0.01$ ) (Table). The mean degree of functional limitation increased with tobacco consumption, although this difference was not statistically significant ( $47.9 \pm 12.1$ vs. $45.1 \pm 11.5$ vs. $44.8 \pm 13.7$ respectively; $p=0.2)$. However, regression analysis showed a statistically significant correlation between smoking and functional limitation $(r=0.096 ; p=0.02)$.

Relationship between tobacco consumption and spinal stiffness levels in patients with ax-SpA

\begin{tabular}{lccccc}
\hline & Smoker & Occasional smoker & Non smoker & $P$ & $\chi^{2}$ \\
\hline Cervical stiffness & $84.2 \%$ & $77.1 \%$ & $73.1 \%$ & 0.171 & 9.044 \\
Dorsal stiffness & $76.0 \%$ & $76.6 \%$ & $72.4 \%$ & 0.408 & 6.141 \\
Lumbar stiffness & $89.0 \%$ & $93.8 \%$ & $83.5 \%$ & 0.002 & 20.518 \\
\hline
\end{tabular}

Source: Spanish Atlas.

Conclusions: Smoking in patients with ax $\mathrm{SpA}$ is associated to greater stiffness in the lumbar region, but is not related to stiffness in the cervical or dorsal regions. Additionally, smoking is associated to the degree of functional limitation in these patients.

Acknowledgements: This project has been supported by Novartis

Disclosure of Interest: None declared

DOI: 10.1136/annrheumdis-2017-eular.6519

\section{SAT0413 INFECTIOUS PROFILE IN A TUBERCULOSIS-ENDEMIC POPULATION WITH SPONDYLOARTHROPATHIES}

M.A. Alzate $^{1,1}$, F. Ramirez ${ }^{2}$, F. Vargas ${ }^{2}$, D. Hernandez-Parra ${ }^{1}$, J.C. Salazar-Uribe ${ }^{3}$, P. Ortiz-Salazar ${ }^{1}$, R. Pineda ${ }^{1}$ on behalf of Artmedica IPS, Medellin, Colombia. ${ }^{1}$ Clinical information group; ${ }^{2}$ Rheumatology division, Artmedica IPS; ${ }^{3}$ School of Statistics, Faculty of Sciences, National University of Colombia, Medellin, Colombia

Background: Screening latent tuberculosis (TB) and other opportunistic infections in patients with spondyloarthropathies ( $\mathrm{SpA}$ ) with biologic or immunosuppression therapy is important in highly endemic population (1).

Objectives: To assess the prevalence of latent and active TB, hepatitis $B$, hepatitis C, HIV and Syphilis in a colombian cohort with SpA, as well as evaluate differences between treatments.

Methods: A cross-sectional study was conducted in 621 patients with SpAs, in whom TB, hepatitis B, hepatitis C, HIV and syphilis screening was analyzed based on type of diagnosis. Differences among immunomodulatory therapies were assessed. Statistical association was examined by means of Chi-square tests, Mann-Whitney test, and logistic regression analyses.

Results: The prevalence of latent and active TB in this cohort were $63,1 \%$, and $2,9 \%$, respectively. Significant differences were found in proportions of latent and active TB among types of SpAs, indicating a positive association with AS. A high

Table 1. Infectious profile in colombian patients with SpAs

\begin{tabular}{|c|c|c|c|c|c|c|c|c|c|}
\hline & \multicolumn{2}{|c|}{$\begin{array}{c}\text { All } \\
\mathrm{N}=621\end{array}$} & \multicolumn{2}{|c|}{$\begin{array}{c}\text { AS } \\
N=340\end{array}$} & \multicolumn{2}{|c|}{$\begin{array}{c}\mathrm{PsA} \\
\mathrm{N}=222\end{array}$} & \multicolumn{2}{|c|}{$\begin{array}{l}\text { Und SpA } \\
\mathrm{N}=59\end{array}$} & \multirow[t]{2}{*}{$\mathrm{p}$-value } \\
\hline & $\mathrm{N}$ & $\%$ & $\mathrm{~N}$ & $\%$ & $\mathrm{~N}$ & $\%$ & $\mathrm{~N}$ & $\%$ & \\
\hline Latent TB & $251 / 398$ & 63,1 & $156 / 244$ & 63,9 & $76 / 126$ & 60,3 & $19 / 28$ & 67,9 & 0,009 \\
\hline Positive TST before & & & & & & & & & \\
\hline immunotherapy & $175 / 398$ & 44 & $98 / 244$ & 40,2 & $64 / 126$ & 50,8 & $13 / 28$ & 46,4 & 0,64 \\
\hline TST conversion during & & & & & & & & & \\
\hline immunotherapy & $76 / 398$ & 19,1 & $59 / 244$ & 24,2 & $13 / 126$ & 10,3 & $4 / 28$ & 14,3 & $<.0001$ \\
\hline Active TB & 18 & 2,9 & 12 & 3,5 & 4 & 1,8 & 2 & 3,4 & 0,03 \\
\hline $\begin{array}{l}\text { Latent TB conversion to } \\
\text { active TB }\end{array}$ & 7 & 1,1 & 6 & 1,8 & 1 & 0,4 & 0 & - & 0,04 \\
\hline $\begin{array}{l}\text { Active TB during } \\
\text { immunotherapy }\end{array}$ & 11 & 1,8 & 10 & 2,9 & 1 & 0,4 & 0 & - & 0,008 \\
\hline Hepatitis B & $11 / 400$ & 2,8 & $4 / 241$ & 1,7 & $6 / 128$ & 4,7 & $1 / 31$ & 3,2 & 0,32 \\
\hline Hepatitis C & $2 / 400$ & 0,5 & $2 / 241$ & 0,8 & $0 / 128$ & - & $0 / 31$ & - & 0,61 \\
\hline VDRL test & $2 / 285$ & 0,7 & $1 / 167$ & 0,6 & $1 / 94$ & 1,1 & $0 / 24$ & - & 0,38 \\
\hline HIV & $3 / 330$ & 0,9 & $2 / 197$ & 1 & $0 / 111$ & - & $1 / 22$ & 4,5 & 0,14 \\
\hline
\end{tabular}

Ankylosing spondylitis (AS), psoriatic arthritis (PsA), undifferentiated spondyloarthritis (Und SpA), tuberculin skin test (TST). 